\title{
Genetic parameters for resistance to the Salmonella abortusovis vaccinal strain Rv6 in sheep
}

\author{
Carole R. Moreno ${ }^{\mathrm{a} *}$, Frédéric LAnTIER ${ }^{\mathrm{c}}$, \\ Patricia Berthon ${ }^{c}$, Anne V. Gautier-Bouchardon ${ }^{c}$, \\ Roger BoIvin ${ }^{\mathrm{c}}$, Isabelle LANTIER ${ }^{\mathrm{c}}$, Jean-Claude BRUNEL ${ }^{\mathrm{b}}$, \\ Jean-Louis WeISBECKER ${ }^{b}$, Dominique FranÇOIS ${ }^{a}$, \\ Jacques BourX $^{\mathrm{a}}$, Jean-Michel ELSEN ${ }^{\mathrm{a}}$ \\ a Station d'amélioration génétique des animaux, \\ Institut national de la recherche agronomique, \\ BP 27, 31326 Castanet-Tolosan Cedex, France \\ $\mathrm{b}$ Domaine de Bourges-La Sapinière, \\ Institut national de la recherche agronomique, 18390 Osmoy, France \\ ${ }^{\mathrm{c}}$ Laboratoire de pathologie infectieuse et immunologie, \\ Institut national de la recherche agronomique, BP 1, 37380 Nouzilly, France
}

(Received 30 April 2002; accepted 8 October 2002)

\begin{abstract}
An experimental population (1216 lambs from 30 sires) of the Inra401 sheep was created in an Inra flock to allow QTL detection for susceptibility to Salmonella infection, wool and carcass traits. The Inra401 is a sheep composite line developed from two breeds: Berrichon du Cher and Romanov. At 113 days of age on average, the lambs were inoculated intravenously with $10^{8}$ Salmonella abortusovis Rv6 (vaccinal strain). They were slaughtered 10 days after the inoculation. Several traits were measured at inoculation and/or slaughtering to estimate the genetic resistance of the lambs to Salmonella infection: specific IgM and IgG1 antibody titres, body weight loss, spleen and pre-scapular node weights and counts of viable Salmonella persisting in these organs. This paper presents a quantitative analysis of the genetic variability of the traits related to salmonellosis susceptibility. The heritabilities of the traits varied between 0.10 and 0.64 (significantly different from zero). Thus, in sheep as well as in other species, the determinism of resistance to Salmonella infection is under genetic control. Moreover, the correlations between the traits are in agreement with the known immune mechanisms. The genetic variability observed should help QTL detection.
\end{abstract}

genetic parameters / Salmonella / sheep / disease resistance

\footnotetext{
* Correspondence and reprints

E-mail: moreno@toulouse.inra.fr
} 


\section{INTRODUCTION}

In humans and animals, the Salmonella species are facultative intracellular bacteria that are responsible for several pathologies: pneumonia, abortion, enteritis, septicaemia, etc. [26]. Clinical manifestations depend on both the host species and the serotype causing the infection [15]. Some Salmonella serotypes, like the serovars Enteritidis and Typhimurium, infect a number of species including humans and then pose serious problems of food safety [13]. The Salmonella enterica serovar Abortusovis (thereafter simplified as S. abortuso$v i s$ ) is pathogenic for sheep and goats, only. It can cause major animal health problems: abortion of ewes and death of lambs [36].

The mechanisms underlying genetic resistance to salmonellosis have been widely studied, mainly in mice $[32,41,46]$ but also in humans $[6,12]$, poultry $[19,20,23,24]$ and cattle [1]. In mice, it has been demonstrated that resistance to salmonellosis is under the control of several loci $[32,46]$ including the NRAMP1 gene located on chromosome 1 , which plays a major role [41,50]. In humans, the NRAMP1 gene has been located on chromosome 2 [12] and influences the resistance to intracellular pathogens such as Mycobacteria [6]. In poultry, the NRAMP1 gene, located on chromosome 7 has also been reported to influence the resistance to salmonellosis $[19,23]$. Moreover, statistical genetic approaches have shown a significant heritability of the response to salmonellosis infection in this species [20,24]. In sheep, the NRAMPI gene has been cloned and located on chromosome $2[11,40]$, but its role in the resistance to salmonellosis is still to be analyzed and no systematic analysis of the resistance to salmonellosis in ruminants has been published yet.

To study the susceptibility to $S$. abortusovis in sheep farm conditions, we used a vaccinal $S$. abortusovis Rv6 strain [28] which allowed work without any risk of spreading the disease. The experiment began in 1993 on 1216 vaccinated lambs belonging to an Inra401 flock. The aim of this experiment was to analyze the genetic variability of the response to salmonellosis infection in two steps: estimation of genetic parameters and a further QTL detection approach using molecular markers. In this paper, we focused on the genetic control of the response to the vaccinal strain using an estimation of genetic parameters (heritability and genetic correlations).

At the same time, the populations were observed for economic traits: body growth and wool traits [2], as well as carcass traits [33].

\section{MATERIALS AND METHODS}

\subsection{Experimental population}

The experimental population was a flock of the Inra401 sheep, a synthetic line bred at the Bourges-La-Sapinière (France) experimental farm. This sheep 
Table I. Number of offspring, sires and dams by series.

\begin{tabular}{lccccr}
\hline Sex & $\begin{array}{c}\text { Batch 1 } \\
\text { (mating in } \\
\text { October 94) }\end{array}$ & $\begin{array}{c}\text { Batch 2 } \\
\text { (mating in } \\
\text { July 95) }\end{array}$ & $\begin{array}{c}\text { Batch 3 } \\
\text { (mating in } \\
\text { October 95) }\end{array}$ & Total \\
\hline Parents & M & 15 & 30 & 15 & $\mathbf{3 0}$ \\
& F & 255 & 275 & 252 & $\mathbf{6 9 7}$ \\
\hline Offspring & M & 198 & 337 & 172 & 707 \\
& F & 218 & 0 & 204 & 422 \\
& M + F & 416 & 337 & 376 & $\mathbf{1 1 2 9}$ \\
\hline
\end{tabular}

line was created from reciprocal crosses between Berrichon du Cher and Romanov animals, followed by four generations of synthetic crosses without any selection from 1970 to 1980 [43]. The Berrichon du Cher and Romanov breeds show opposite performances concerning production traits as well as the response to salmonellosis infection [30]. A substantial fraction of this interbreed variability is probably still present in the Inra401 line, due to the genetic management of the population based on a rotation between 15 families, with the aim of preserving genetic variability. Our experimental population was thus probably genetically variable enough to insure success for QTL detection.

The design used was based on a series of sire half sib families [35]. Simulations (not shown) were done to optimize the family structure. They were made up of 30 sires each with 40 progeny. Practically, 1216 animals were put into three batches (mating in October 1994, July 1995 and October 1995) and 1129 sheep were measured for resistance traits. The number of female progeny was lower than the number of males due to the fact that the females from batch 2 were kept for replacement on the farm (Tab. I).

\subsection{Phenotypic measurements}

Table II presents descriptions and abbreviations for the measured traits.

\subsubsection{Bacterial strain}

Due to the restraints related to the inoculation of a virulent $S$. abortusovis strain (breeding in a protected environment, full destruction of the carcasses, ...), the vaccinal strain of $S$. abortusovis, Rv6 was used. The Rv6 strain is a spontaneous double mutant with attenuated virulence selected from a spontaneous mutant, itself streptomycin-dependent, obtained from the Salmonella abortusovis $15 / 5$ virulent strain [28,37]. As compared to the virulent strain, this strain induces a similar but weaker response [16,21,28,29]. 
Table II. Notations of variables.

\begin{tabular}{ll}
\hline Notation & Measured variable \\
\hline IgG1 $_{0}$ & IgG1 titre at vaccination \\
IgG1 & IgG1 titre at slaughter \\
Var-IgG1 & IgG1 titre variation between vaccination and slaughter \\
$\mathrm{IgM}_{0}$ & IgM titre at vaccination \\
$\mathrm{IgM}_{7}$ & IgM titre at slaughter \\
Var-IgM & IgM titre variation between vaccination and slaughter \\
\hline BgLN & Bacterial count per gram in the left pre-scapular node \\
BgRN & Bacterial count per gram in the right pre-scapular node \\
BgS & Bacterial count per gram in the spleen \\
BgS01 & Presence/absence of bacteria in the spleen \\
\hline WtLN & Left pre-scapular node weight \\
WtRN & Right pre-scapular node weight \\
WtS & Spleen weight \\
WtrS & Spleen weight stated in the body weight at the vaccination fraction \\
\hline loss-Wt & Body weight loss between vaccination and slaughter \\
\hline
\end{tabular}

Preliminary experiments were conducted to choose the optimal conditions (traits and timing) for measuring the response to S. abortusovis Rv6 with respect to practical husbandry conditions $[8,30]$.

\subsubsection{Experimental design}

In the experimental farm, there was no history of clinical signs related to salmonella. However 20 animals (non-infected by S. abortusovis Rv6) were used to control the status of the experimental flock and no lymph node or spleen contamination by any bacteria was observed.

Up to 45 days of age, the lambs were fed milk naturally or artificially. After weaning, they were raised in a sheep barn where the males and females were separated. When they reached a given weight (38 kg for the males and $32 \mathrm{~kg}$ for the females), a blood sample was taken (Day 0 (D0)) and each lamb was intravenously inoculated with $10^{8}$ bacteria from the vaccinal Rv6 strain in the left jugular vein. The mean age of the lambs was then 113 days. They were weighed at D7, a second blood sample was collected and they were slaughtered at D10. After slaughtering, the right and left pre-scapular lymph nodes and the spleen were sampled in order to measure the bacterial load. The blood taken at D0 and D7 was used to evaluate the anti-Salmonella IgM and IgG1 antibody response. 


\subsubsection{Antibody titres}

The anti-S. abortusovis antibody titres of sera collected at D0 and D7 were determined by direct ELISA assays according to Berthon et al. [9] using inactivated whole $S$. abortusovis as the antigen. Class specific antisheep IgG1 and IgM monoclonal antibodies $[4,5]$ were kindly provided by Dr. K.J. Beh (CSIRO, Glebe, Australia). Each serum was tested in duplicate. As determined by preliminary studies, a 1/900 dilution of serum was chosen as clearly differentiating DO and D7 IgG1 and IGM titres in sera from immunized or naïve sheep. The specificity of the assay for anti-S. abortusovis antibodies was assessed through kinetic studies of the response to vaccination or infection and the use of sera from sheep infected with unrelated pathogens (unreported data). In the first step, the ELISA results were given in OD (optical density) corrected for the baseline level of the test as determined by negative control wells (including all reagents, except the tested serum). In order to be able to compare the assays performed at various dates, a positive control, a hyperimmune serum from a sheep vaccinated twice with the $S$. abortusovis strain Rv6, was included in each test. It was verified that the variation of this positive control never exceeded 5\% of the expected value. Antibody titres were given in the percent of the mean value of the positive control.

The IgG1 and IgM titres at D0 and D7 sera will be referred to as IgG1 $\mathbf{1}_{\mathbf{0}}$, $\mathbf{I g M}_{\mathbf{0}}$ and $\mathbf{I g G 1}_{\mathbf{7}}, \mathbf{I g M}_{\mathbf{7}}$. The response to vaccination given by the antibody titre variations will be referred to as Var-IgG1 and Var-IgM.

\subsubsection{Bacterial enumeration}

The number of bacteria colonizing the spleen, the right and left pre-scapular lymph nodes was estimated by a classical bacteriological protocol [27]. The organs were collected in the slaughterhouse and were stored at $-20^{\circ} \mathrm{C}$ until their treatment within 2 months, a period of time during which the Salmonella population in stored tissues is known to remain constant (unpublished results). After thawing, the samples were superficially burned, ground and diluted. Aliquots of the homogenates and of their dilutions were cultured on a selective medium (SS, Biomérieux). After a $48 \mathrm{~h}$-incubation at $37^{\circ} \mathrm{C}$, the $S$. abortusovis colonies were enumerated. From these enumerations, the number of bacteria per gram in the spleen (BgS) and the right and left pre-scapular lymph nodes (BgRN and BgLN) were computed. Since the number of bacteria in the spleen was null in $70.5 \%$ of the samples, then the binary trait, the presence or absence of bacteria (BgS01) was also considered.

\subsubsection{Body and tissue weights}

Weights were also considered to evaluate the effect of vaccination against salmonellosis: body weight at D0 and D7 ( $\mathbf{W t}_{\mathbf{0}}$ and $\left.\mathbf{W t}_{\mathbf{7}}\right)$, weight of the lymph 
Table III. Basic statistics.

\begin{tabular}{lccrrrr}
\hline & Unit & Numbers & Mean & $\begin{array}{r}\text { Standard } \\
\text { deviation }\end{array}$ & Minimum & Maximum \\
\hline IgG1 & $\%$ & 1126 & 8.7 & 6.5 & 1 & 50 \\
Var-IgG1 & $\%$ & 1123 & 15.0 & 16.1 & -9 & 100 \\
IgM & $\%$ & 1126 & 17.7 & 8.2 & 1 & 49 \\
Var-IgM & $\%$ & 1123 & 87.8 & 36.1 & -2 & 195 \\
BgLN & $\mathrm{g}^{-1}$ & 1128 & 1046.2 & 2302.1 & 0 & 30350 \\
BgRN & $\mathrm{g}^{-1}$ & 1128 & 965.8 & 2163.9 & 0 & 24106 \\
BgS & $\mathrm{g}^{-1}$ & 1127 & 1.8 & 4.7 & 0 & 56.3 \\
WtLN & $\mathrm{g}$ & 1126 & 4.6 & 1.6 & 1.5 & 13.7 \\
WtRN & $\mathrm{g}$ & 1126 & 4.1 & 1.3 & 1.4 & 11.0 \\
WtS & $\mathrm{g}$ & 1127 & 45.8 & 9.3 & 23.7 & 98.6 \\
WtrS & $\mathrm{mg} \cdot \mathrm{kg}^{-1}$ & 1127 & 12.7 & 2.3 & 7.1 & 24.2 \\
loss-Wt & $\mathrm{kg}$ & 1129 & -0.2 & 2.1 & -4.7 & 7.6 \\
\hline
\end{tabular}

nodes and the spleen sampled at slaughtering (WtS, WtRN, WtLN). Despite the initial objective of $32 \mathrm{~kg}$ for the females and $38 \mathrm{~kg}$ for the males, the weight at vaccination $\mathrm{Wt}_{0}$, varied between animals, and the spleen weights were also expressed as the proportion of $\mathrm{Wt}_{0}$ : the relative spleen weight (WtrS). Finally the body weight loss between D0 and D7 (loss-Wt) was itself considered as a trait responding to vaccination. Indeed, the growth rate after vaccination was largely affected since the gain of weight varied from -8 to $+5 \mathrm{~kg}$ within 7 days while it was about +1 to $+6 \mathrm{~kg}$ for uninfected control animals (Tab. III).

The elementary statistics concerning all traits are given in Table III.

\subsection{Statistical methods}

\subsubsection{Analysis of the trait distribution}

Deviation from the normality of the traits was assessed from an asymmetry coefficient g1 and kurtosis coefficient g2 [49], and from the Shapiro-Wilk normality test [47] (SAS ${ }^{\circledR}$ UNIVARIATE procedure [44]).

The traits showing a strong deviation from normality were transformed using the logarithmic transformation $\left(\log _{10}(X)\right)$. The transformation was performed on the $X=Y+k$ variable, where $Y$ was the measured trait and $k$ is the minimum integer value such as $X$ is always positive, in order to allow the transformation whatever the $Y$ value. The transformed data was referred to as $\log -Y(e . g$. Log-WtLN). 
The bacterial colonisation was also estimated by the all-or-none variable: presence/absence of the bacteria in the spleen $(\mathrm{BgS01})$, avoiding the strong non normality of this trait showing a very high proportion of 0 values.

\subsubsection{Continuous variable analysis: Gaussian model}

Under the hypothesis of a normal distribution of the traits, the mixed linear model [38] was used to estimate the phenotypic correlations and the genetic parameters, heritabilities and genetic correlations. The variance components were obtained using the REML method with the Groeneveld VCE [22]. The robustness of the results was evaluated testing different mixed models, unior multi-traits, with sire or animal random effects, with or without a maternal effect. The genetic parameters presented were obtained considering five generations in the pedigree.

For practical reasons, the fixed effects included in the model were chosen using a first model where all the effects (environment and sire) were fixed using the $\mathrm{SAS}^{\circledR}$ GLM procedure [45]. A fixed effect was kept when it was significant at a level $P<0.05$. The same initial effects were tested for all traits: sex ( 2 levels), batch (3 levels), birth rank-suckling type (5 levels: born-suckled single, born multiple-suckled single, born-suckled double, born triplet or quadruplet-suckled double, artificially suckled) and an age class at vaccination (4 levels: under 99 days, 99 to 115 days, 115-130, above 130 days of age). Weight class at vaccination was also tested within both sexes to verify that it had no effect on the measured traits. Three categories were created for the females (body weight less than $31 \mathrm{~kg}, 31$ to $33 \mathrm{~kg}$, more than $33 \mathrm{~kg}$ ) and for the males (body weight less than $37 \mathrm{~kg}, 37$ to $39 \mathrm{~kg}$, more than $39 \mathrm{~kg})$.

\subsubsection{Binary variables analysis: threshold model}

The binary trait presence/absence of the bacteria in the spleen (BgS01) has been described by the Wright model [51], which hypothesizes a normal variable $\left(X_{i}\right)$ underlying the observations $\left(Z_{i}=0\right.$ or 1$)$ and a threshold $(s)$ for this variable so that $Z_{i}=0$ if $X_{i}<s, Z_{i}=1$ if $X_{i} \geq s$. Following this model, the variance components were estimated directly on the underlying scale. The software used was developed by Chapuis (pers. comm.) following the methodology of Janss and Foulley [25] and the EM algorithm following Simianer and Schaeffer [48]. This software allows a bivariate analysis for a binary trait and a continuous trait under a sire model.

As for the normal model, the fixed effects to consider for estimating the genetic parameters were determined using a fully fixed effect model, here with the SAS ${ }^{\circledR}$ GENMOD procedure [3]. The tested effects were the sex, batch, birth-suckling type, age class at vaccination, and sire. Considering the 
significant fixed effects, the heritability of the variable presence/absence of bacteria in the spleen and its correlations with other traits were estimated using the pedigree information from five generations.

\section{RESULTS}

\subsection{Elementary statistics and transformations}

With the exception of the $\operatorname{IgM}$ antibody measurements $\left(\operatorname{IgM} \mathrm{M}_{0}\right.$, var-IgM), trait distribution was significantly different from the normal law (Fig. 1: example of the number of bacteria in the left pre-scapular lymph node). This non normality was mainly due to a strong right asymmetry ( $g_{1}=4.6$ to 5.6) for the number of bacteria per gram in organs (BgLN, BgRN and $\mathrm{BgS})$, a moderate asymmetry $\left(\mathrm{g}_{1}=2.2\right.$ and 1.9$)$ for the $\mathrm{IgG1}$ antibody measurements ( $\mathrm{IgG} 1_{0}$ and var-IgG1) and slight $\left(\mathrm{g}_{1}=0.6\right.$ to 1.3$)$ for the organ weight (WtLN, WtRN and WtS), the relative spleen weight (WtrS) and the body weight loss (loss-Wt). When we used a Log transformation, the asymmetry decreased for all traits having a non-normal distribution $\left(\mathrm{g}_{1}=-0.8\right.$ to 1.6$)$. As a consequence, all traits except the $\operatorname{IgM}$ measurements $\left(\operatorname{IgM}_{0}\right.$, Var-IgM) were $\log$ transformed in the following analysis.

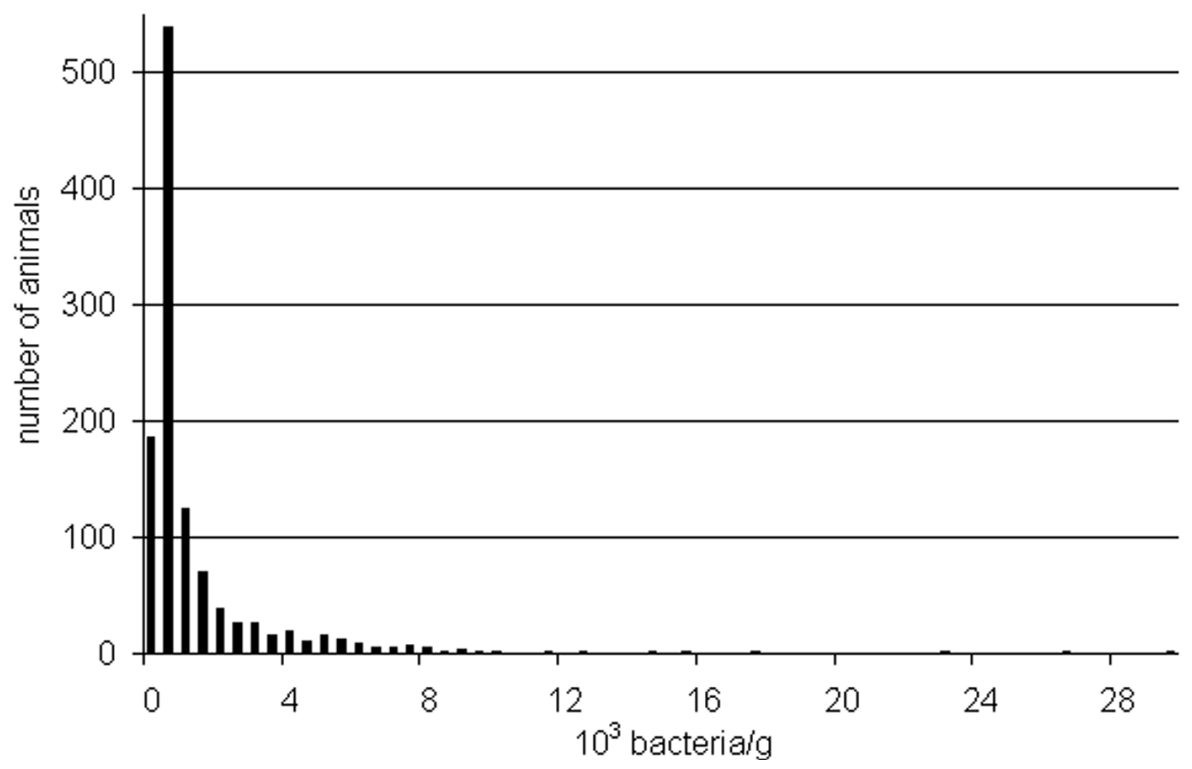

Figure 1. Bacterial count per gram in the left pre-scapular node. 
Table IV. Significance of tested effects (continuous and binary traits).

\begin{tabular}{lccccccc}
\hline Variables & $\begin{array}{c}\text { Part of } \\
\text { explained } \\
\text { variance }\end{array}$ & Sex & $\begin{array}{c}\text { Weight } \\
\text { class } \\
\text { within sex }\end{array}$ & $\begin{array}{c}\text { Age } \\
\text { class }\end{array}$ & $\begin{array}{c}\text { Birth rank } \\
\text { suckling } \\
\text { status }\end{array}$ & Batch & Sire \\
\hline IgM $_{0}$ & 0.35 & NS & NS & $* * *$ & NS & $* * *$ & $* * *$ \\
Var-IgM & 0.17 & $*$ & NS & $*$ & NS & $*$ & $* * *$ \\
Log-IgG1 0 & 0.13 & NS & NS & $* *$ & $* *$ & $* * *$ & $* * *$ \\
Log-Var-IgG1 & 0.22 & NS & NS & NS & $*$ & $* * *$ & $* * *$ \\
\hline Log-BgLN & 0.10 & $* *$ & NS & $*$ & NS & NS & $* * *$ \\
Log-BgRN & 0.11 & $* *$ & NS & $* * *$ & NS & NS & $* * *$ \\
Log-BgS & 0.05 & $* *$ & NS & NS & NS & NS & $*$ \\
\hline Log-WtLN & 0.17 & $* * *$ & NS & $* * *$ & NS & $* * *$ & $* * *$ \\
Log-WtRN & 0.18 & $* * *$ & NS & $* * *$ & NS & $* * *$ & $* * *$ \\
Log-WtS & 0.30 & $* * *$ & $* * *$ & $* * *$ & $* * *$ & $* *$ & $* * *$ \\
Log-WtrS & 0.18 & $* * *$ & NS & $* * *$ & $* * *$ & $* *$ & $* * *$ \\
\hline Log-loss-Wt & 0.11 & $* * *$ & $*$ & $* *$ & NS & NS & $* *$ \\
\hline BgS01 ${ }^{2}$ & - & $*$ & - & NS & NS & NS & $*$ \\
\hline a The trait was analyzed with a threshold model; b the proportion of variance \\
explained by the model constituted of significant fixed effects; $(-)$ parameters absent \\
from the model. The levels of significance of the fixed effects are shown with \\
asterisks. $* * * P$ \\
\hline
\end{tabular}

\subsection{Fixed effects}

The levels for the significance of the tested fixed effect are given in Table IV.

The effect of body weight at vaccination was significant for Log-WtS but not for Log-WtrS. Given these observations, the trait finally analyzed was the logarithm of the relative spleen weight (Log-WtrS).

The sex effect was found to be significant for most of the measured traits except for $\operatorname{IgM}_{0} \log -\operatorname{IgG} 1_{0}$, Log-Var-IgG1. When compared to females, the males had on average a lower IgM response but more bacteria in their prescapular lymph nodes and their spleen. Their organs were heavier and they gained more weight after vaccination.

Age at vaccination had a significant effect on most of the traits. The older the animal was, the higher was the level of $\operatorname{IgM}$ at vaccination $\left(\operatorname{IgM}_{0}\right)$. A similar but less clear situation was observed for $\log -\operatorname{IgG} 1_{0}$. After vaccination, age had a reverse and lower effect on the IgM level variation: the younger the animal, the higher the IgM level variation, and the higher were its bacterial counts in the lymph nodes (at 5\% level) and in the spleen (non significant). 
Finally, the younger the animal was, the heavier its organs were at slaughtering and the lower its growth was between vaccination and slaughtering.

Batch had a significant effect on antibody responses and organ weights, but not on the bacterial enumeration.

The birth-suckling type had a significant effect for only four traits: LogIgG1 $1_{0}$, Log-Var-IgG1, Log-WtS and Log-WtrS. The more lambs the dam suckled, the lower the IgG1 basal titre of the lamb. Lambs suckled artificially behaved as single suckled lambs for $\log -\operatorname{IgG} 1_{0}$ and had on average a heavier spleen.

As far as the number of bacteria in the spleen was concerned both continuous $(\log -\mathrm{BgS})$ and discrete $(\mathrm{BgS01})$ models revealed the same significant effects, at similar levels.

\subsection{Estimations of genetic parameters and phenotypic correlations}

In general, the heritabilities (Tab. V) were found to be moderate to high, with the exception of the body weight loss between vaccination and slaughtering (log-loss-Wt) and, of Log-IgG1 $1_{0}$ and $\log -\mathrm{BgS}$, which were low $(0.10,0.14$ and 0.06 , respectively). The IgM level at vaccination and the spleen weight were highly heritable ( 0.64 and 0.54 respectively). The genetic correlations were generally of the same sign and higher than the phenotypic correlations. In particular, the genetic correlation between the number of bacteria in the right and left pre-scapular lymph nodes was close to 1 and the phenotypic correlation was slightly lower. The same trends were observed concerning the correlations between the weights of these organs. The genetic and phenotypic correlations between Var-IgM and Log-Var-IgG1 were high. The genetic and phenotypic correlations between $\operatorname{IgM}_{0}$ and body weight loss between vaccination and slaughtering were negative, but this trait was positively correlated with all other traits. Finally, the number of bacteria in the spleen showed high genetic correlations, negative with $\operatorname{IgM}_{0}$ level and positive with the number of bacteria in the lymph nodes.

For continuous traits, the estimations were similar whatever the mixed model considered: uni- or multi-trait, sire or animal random effect, except for Log$\operatorname{IgG1} 1_{0}$. The heritability of this trait was 0.14 from a multi-trait sire model, and 0.33 from a multi-trait animal model. The genetic correlations between Log$\mathrm{IgG1} 1_{0}$ and other traits differed between the two models. Because the genetic structure of the population did not enable a correct estimation of the genetic maternal effect (Appendix), the pedigree information from the dam side was not included, estimating under a sire model the heritability of $\log -\operatorname{IgG} 1_{0}$ and its genetic correlations with other traits (1st row and 1st column of Tab. V). As far as the other traits were concerned, the parameters presented in Table $\mathrm{V}$ were estimated under a multi-trait animal model. 


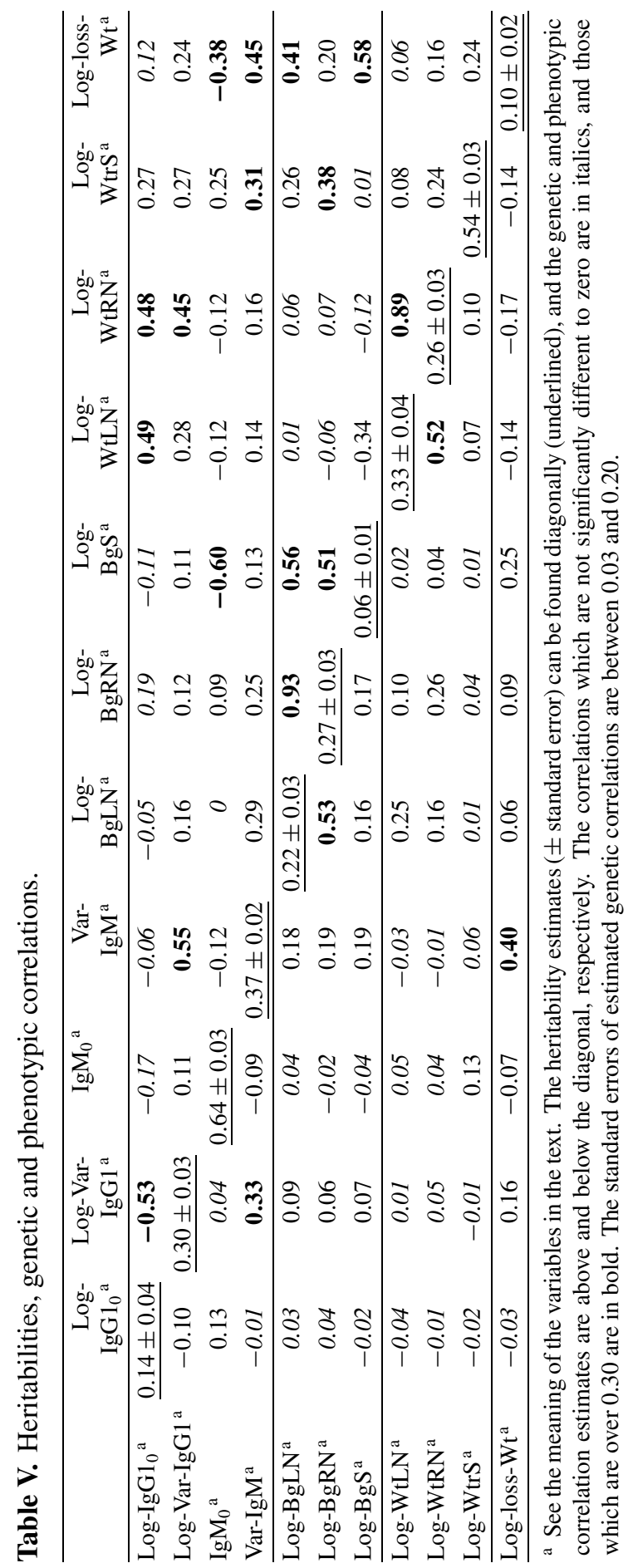




\section{DISCUSSION}

\subsection{The experimental design}

In order to be able to predict the response to infection as much as possible, many traits were considered. The age at measurement was chosen according to previous observations: the maximum level of bacterial infection in the spleen was observed a week after subcutaneous inoculation in sheep [27] and subcutaneous or intravenous inoculation in mice [29], and the IgG1 humoral response was soon starting one week after infection [9]. Considering these observations and practical husbandry restraints, the chosen slaughtering time corresponded to the end of the spleen infection (10 days after inoculation) and to the beginning of the IgG1 response (7 days after inoculation). On average, the measured traits exhibited a large phenotypic variation (Tab. III), allowing correct genetic analysis. However, a large proportion of bacterial enumerations revealed an absence of infection, with $20 \%$ and $70 \%$ of null values in the lymph nodes and in the spleen, respectively. The simplest explanation is that data were collected at the end of the infection process, a large part of the animals having cleared the bacteria from their spleen (one of the organs primarily infected following an intravenous inoculation). From a statistical point of view, the number of bacteria in the spleen is the only trait causing difficulties for the genetic analysis, being only slightly variable and exhibiting a strong asymmetrical distribution, even after a mathematical transformation.

A major hypothesis, sustained by the absence of Salmonella clinical episodes or serology in this flock, was that the animals had no previous infection with Salmonella. To test this hypothesis, the basal levels of specific IgG1 and IgM antibodies were measured just before vaccination. A phenotypic variability of these traits was observed (Tab. III), but their phenotypic correlations with the traits measuring the response to infection were low to null (Tab. V). This supported the hypothesis and preliminary observations. Detection of antiSalmonella antibodies at a baseline level is known to be due to stimulation of the sheep immune system by normal gut flora, for instance with cross reactive antigens from frequent Enterobacteria such as Escherichia coli.

\subsection{Antibody production}

Anti-Salmonella antibody titres were measured at two stages: before vaccination as a basal level and before slaughtering as a response to inoculation.

The $\mathrm{IgM}_{0}$ and $\mathrm{Log}-\mathrm{IgG} 1_{0}$ showed very different genetic determinisms (heritabilities and correlations with other traits). $\log -\operatorname{IgG} 1_{0}$ had a low heritability and was genetically poorly correlated with other traits, with the exception of the Log-Var-IgG1. This last correlation suggests that animals which produce a high basal IgG1 level, respond to new infection with a lower production of IgG1 
antibodies. Additional genetic analysis indicated a genetic variability of the maternal effect and a strong correlation between the direct and maternal effect on $\log -\operatorname{IgG} 1_{0}$ (Appendix). The most probable explanation to this observation is that a part of the IgG1 circulating in the lambs was of maternal origin. Indeed IgG1 antibodies transmitted by the dam to the lamb through the colostrum persist for several weeks [34]. At 3-4 months of age, when the lambs were observed, some of these maternal antibodies could have still been present in the lamb.

The IgM basal titre had a high heritability value and was highly genetically correlated with some traits that measure resistance to salmonellosis. Our results indicated common mechanisms controlling the IgM basal level and the bacteria clearance in the spleen, as well as body weight loss during the infection period. The animals with the highest levels of IgM at D0, before Salmonella infection, were the less infected after experimental inoculation with the vaccinal strain of $S$. abortusovis. It should be investigated whether or not this measurement (IgM antibody response to normal gut flora or mild contaminants, which would avoid any challenge) is a good predictor for selection purposes.

Both IgG1 and IgM humoral responses to infection were observed. After a primary infection, IgM production makes the first response followed by IgG1 production. Observing high genetic and phenotypic correlations between these traits is consistent with our knowledge about the common immune mechanisms inducing IgM and IgG1 responses. Moreover, the genetic and phenotypic correlations between Var-IgM and Log-Var-IgG1 and bacterial counts, as well as body weight loss, indicate that high antibody responders have more bacteria in the lymph nodes and are losing more weight. A simple explanation could be that animals with greater infection had a higher stimulation of their immune system.

A number of estimations of genetic parameters for the antibody response to antigens have been previously published. In sheep, Berggren-Thomas et al. [7] found heritabilities between 0.28 and 0.38 for the humoral response to ovalbumin antigens. In other species, multi-generation diverging selection for antibody responses was successful. Heritability of antibody response to sheep red blood cells was found to be between 0.18 and 0.36 in mice depending on the design [10], and was estimated at 0.31 in poultry [39]. In pigs, the heritabilities of these responses to various antigens were observed to be between 0.15 and 0.75 [31]. In mice, experimental infection of $N R A M P 1$ congenic lines indicated that the IgM and IgG1 anti-Salmonella antibody responses were lower in the susceptible line [18]. These results are consistent with our observations since IgM and IgG1 titre variations were heritable and correlated.

All these studies showed that antibody response was heritable and that heritability values were similar to those observed in sheep. Moreover, since the genes affecting antibody production were identified in mice [42], it should 
be possible to use a comparative mapping approach to detect QTL for IgM and IgG1 titre variations from our design in the future.

\subsection{General response}

The other recorded traits measured more overall responses: the number of bacteria in the lymph nodes and spleen 10 days after inoculation, the weight of these organs, and body weight loss between vaccination and slaughtering. This latter parameter could be considered as a measure of resilience. Our observations suggested that an animal that maintained its growth (high resilience) had a higher IgM basal level but a lower antibody response and a lower number of bacteria in the observed organs.

From our results, the genetic mechanisms for bacterial clearance were similar in the left and right pre-scapular lymph nodes. The corresponding measurements are thus indicators of the general and not of the local response (the vaccination was always performed on the left side).

The genetic parameters for the bacterial count in the spleen $(\log -\mathrm{BgS})$, estimated with the VCE software and assuming the normality of the distribution, may be questionable. To check these results, the genetic parameters were also estimated for all or none of the presence/absence of bacteria traits (BgS01), using software dealing with a binary and a normally distributed trait (Hervé Chapuis, pers. comm.). Genetic correlations between $\mathrm{Log}-\mathrm{BgS}$ or $\mathrm{BgS01}$ and the other traits are close with a notable exception of Log-BgRN ( 0.51 versus $0.15)$ without any obvious explanations. Heritability of BgS01 estimated with the threshold model $\left(h^{2}=0.09\right)$ is classically higher than the Gaussian model estimate by $\log -\mathrm{BgS}$ heritability $\left(h^{2}=0.06\right)$.

In the literature, a number of genetic parameters concerning pathogen enumerations have been published but only a few deal with salmonellosis [20, 24]. In chickens inoculated with Salmonella enteritidis, the heritability of the number of bacteria in the spleen was found to be 0.10 [20] and the value for caeca 0.08 [24]. In sheep, counts have been widely used for studying resistance to parasitism [17]. But, to our knowledge, nothing has been published about salmonellosis.

\section{CONCLUSION}

A number of traits were measured in a large number of animals to obtain a better description of the immune parameters related to Salmonella colonisation: an immune humoral response, bacteria clearance in lymphoid organs, etc. As in mice and poultry, we found that sheep resistance to salmonellosis has a genetic component: the heritabilities differed significantly from zero, ranging from 0.10 to 0.64 . Correlations between the measured traits are consistent with 
known immune mechanisms. In the near future, our observations will be used for the detection of QTL, enabling a more direct comparison with the results obtained in mice [46]. The very high heritability of the basal IgM level and the correlation between this trait and other measurements of resistance could suggest applications for selection. Further studies are nevertheless needed to check that selection on "natural antibody" production could not induce higher susceptibility to other diseases [14].

\section{ACKNOWLEDGEMENTS}

We would like to thank Hervé Chapuis (SYSAAF, Nouzilly) for the use of his software dealing with a bivariate analysis of binary traits and continuous traits. The technicians of the Inra farm, La Sapinière, are gratefully acknowledged for all the practical work at the farm and at the slaughterhouse. The gift of anti-sheep immunoglobulin monoclonal antibodies from Dr. K.J. Beh (CSIRO, Glebe, Australia) is greatly acknowledged. This work was partly financed by an AIP GRAM from Inra.

\section{REFERENCES}

[1] Adams L.G., Templeton J.W., Genetic resistance to bacterial disease of animal, Rev. Sci. Tech. 17 (1998) 200-219.

[2] Allain D., Lantier I., Elsen J.M., François D., Brunel J.C., Weisbecker J.L., Schibler L., Vaiman D., Cribiu E., Gautier A., Berthon P., Lantier F., A design aiming at detecting QTL controlling wool traits and other traits in the Inra401 sheep line, Proceedings of the 6th World Congress on Genetics Applied to Livestock Production, University of New England, Armidale, 11-16 January 1998, Vol. 24, Australia, pp. 51-54.

[3] Allison P.D., Logistic regression using the $\mathrm{SAS}^{\circledR}$ system: theory and application, Cary, NC, SAS ${ }^{\circledR}$ Institut Inc., 1999, 304 p.

[4] Beh K.J., Monoclonal antibodies against sheep immunoglobulin light chain, IgM and IgA, Vet. Immunol. Immunopathol. 18 (1988) 19-27.

[5] Beh K.J., Production and characterization of monoclonal antibodies specific for sheep IgG subclasses IgG1 or IgG2, Vet. Immunol. Immunopathol. 14 (1987) 187-196.

[6] Bellamy R., Ruwende C., Corrah T., McAdam K.P., Whittle H.C., Hill A.V., Variations in the NRAMPI gene and susceptibility to tuberculosis in West Africans, N. Engl. J. Med. 338 (1998) 640-644.

[7] Berggren-Thomas P.L., Kaatari S., Hohenboken W.D., Shrestha J.N.B., Heaney D.P., Inheritance of active and acquired immunity traits in sheep, J. Anim. Sci. 64 (1987) 1302-1312.

[8] Bernard S., Guilloteau L., Buzoni-Gatel D., Pépin M., Bernard F., Lantier I., Lantier F., Mechanisms of acquired immunity induced by the live-attenuated Salmonella abortusovis (Rv6) vaccine, NATO Advanced Workshop "The biology of salmonella", Messine, 1992. 
[9] Berthon P., Gohin I., Lantier I., Olivier M., Humoral immune response to Salmonella abortusovis in sheep: in vitro induction of an antibody synthesis from either sensitized or unprimed lymph node cells, Vet. Immunol. Immunopathol. 41 (1994) 275-294.

[10] Biozzi G., Mouton D., Heumann A.M., Bouthillier Y., Stiffel C., Mevel J.C., Genetic analysis of antibody responsiveness to sheep erythrocytes in crosses between lines of mice selected for high or low antibody synthesis, Immunology 36 (1979) 427-438.

[11] Bussmann V., Lantier I., Pitel F., Patri S., Nau F., Gros O., Elsen J.M., Lantier F., cDNA cloning, structural organization, and expression of the sheep NRAMP1 gene, Mamm. Genome 9 (1998) 1027-1031.

[12] Cellier M., Govoni G., Vidal S., Kwan T., Groulx N., Liu J., Sanchez F., Skamene E., Schurr E., Gros P., Human natural resistance-associated macrophage protein: cDNA cloning, chromosomal mapping, genomic organization, and tissue-specific expression, J. Exp. Med. 180 (1994) 1741-1752.

[13] Desenclos J.C., Bouvet P., Pierre V., Brisabois A., Fremy S., Lahellec C., Grimont F., Grimont P.A.D., Épidémiologie des infections à Salmonella: tendances récentes en France et en Europe, Bull. Soc. Fr. Microbiol. 11 (1996) 208-215.

[14] Doenhoff M.J., The immune System, in: Axford R.F.E., Bishop S.C., Nicholas F.W., Owen J.B. (Eds.), 2nd edn., Breeding for disease resistance in farm Animals, CAB international, Wallingford, 2000, pp. 47-72.

[15] Ekperigin H.E., Nagaraja K.V., Salmonella, Vet. Clin. North Am. Food Anim. Pract. 14 (1998) 17-29.

[16] Fontaine J.J., Pépin M., Pardon P., Marly J., Parodi A.L., Comparative histopathology of draining lymph node after infection with virulent or attenuated strains of Salmonella abortusovis in lambs, Vet. Microbiol. 39 (1994) 61-69.

[17] Gasbarre L.C., Miller J.E., Genetics of helminth resistance, in: Axford R.F.E., Bishop S.C., Nicholas F.W., Owen J.B. (Eds.), 2nd edn., Breeding for disease resistance in farm animals, CAB international, Wallingford, 2000, pp. 129-152.

[18] Gautier A.V., Lantier I., Lantier F., Mouse susceptibility to infection by the Salmonella abortusovis vaccine strain Rv6 is controlled by the Ity/Nrampl gene and influence the antibody but not the complement responses, Microbial Pathogenesis 24 (1998) 47-55.

[19] Girard-Santosuosso O., Bumstead N., Lantier I., Protais J., Colin P., Guillot J.F., Beaumont C., Malo D., Lantier F., Partial conservation of the mammalian NRAMP1 linkage group on chicken chromosome 7, Mamm. Genome 8 (1997) 614-616.

[20] Girard-Santosuosso O., Lantier F., Lantier I., Bumstead N., Elsen J.M., Beaumont C., Resistance to infection with Salmonella enteritidis phage type 4 three days after intravenous inoculation of 13-week-old chickens is heritable and controlled by the chromosome region carrying the NRAMPl gene, Genet. Sel. Evol. 34 (2002) 211-219.

[21] Gohin I., Olivier M., Lantier I., Pépin M., Lantier F., Analysis of the immune response in sheep efferent lymph during Salmonella abortusovis infection, Vet. Immunol. Immunopathol. 60 (1997) 111-130.

[22] Groeneveld E., VCE4 User's Guide and Reference Manual, Germany, 1997. 
[23] Hu J., Bumstead N., Burke D., Ponce de Leon F.A., Skamene E., Gros P., Malo D., Genetic and physical mapping of the natural resistance-associated macrophage protein 1 (NRAMP1) in chicken, Mamm. Genome 6 (1995) 809-815.

[24] Janss L.L.G., Bolder N.M., Heritabilities of and genetic relationships between Salmonella resistance traits in broilers, J. Anim. Sci. 78 (2000) 2287-2291.

[25] Janss L.L.G., Foulley J.L., Bivariate analysis for one continuous and one threshold dichotomous trait with unequal design matrices and an application to birth weight and calving difficulty, Livest. Prod. Sci. 33 (1993) 183-198.

[26] Kaufmann S.H.E., Raupach B., Finlay B.B., Introduction: microbiology and immunology: lessons learned from Salmonella, Microbes Infect. 3 (2001) 1177-1181.

[27] Lantier F., Kinetics of experimental Salmonella abortusovis infection in ewes, Ann. Rech. Vét. 18 (1987) 393-396.

[28] Lantier F., Pardon P., Marly J., Vaccinal properties of Salmonella abortusovis mutants for streptomycin: Screening with a murine model, Infect. Immun. 34 (1981) 492-497.

[29] Lantier F., Pardon P., Marly J., Immunogenicity of a low-virulence vaccinal strain against Salmonella abortusovis infection in mice, Infect. Immun. 40 (1983) 601-607.

[30] Lantier F., Pitel F., Berthon P., Gautier A., Boivin R., Weisbecker J.L., Brunel J.C., François D., Gellin J., Vu Tien J., Elsen J.M., Contrôle génétique de la résistance aux Salmonellae chez les ovins, Renc. Rech. Ruminants 2 (1995) 311-316.

[31] Mallard B.A., Wilkie B.N., Kennedy B.W., Gibson J., Quinton M., Immune responsiveness in swine: eight generations of selection for high and low immune response in Yorkshire pigs, Proceedings of the 6th World Congress on Genetics Applied to Livestock Production, University of New England, Armidale, 11-16 January 1998, Vol. 27, Australia, pp. 257-264.

[32] McLeod R., Buschman E., Arbuckle L.D., Skamene E., Immunogenetics in the analysis of resistance to intracellular pathogens, Curr. Op. Immunol. 7 (1995) 539-552.

[33] Moreno C., Bouix J., Brunel J.C., Weisbecker J.L., François D., Lantier F., Elsen J.M., Genetic parameter estimates for carcass traits in Inra401 composite sheep strain, Livest. Prod. Science 69 (2001) 227-232.

[34] Mukkur T.K.S., Walker K.H., McDowell G.H., Passive immunisation of neonatal lambs via colostrums and milk of ewes previously immunised with live attenuated Salmonella typhimurium protects neonatal lambs from experimental salmonellosis, Comparative Immunology, Microbiol. Infect. Dis. 21 (1998) 327-336.

[35] Neimann-Sorensen A., Robertson A., The association between blood groups and several production characteristics in three Danish cattle breeds, Acta Agric. Scand. 11 (1961) 163-196.

[36] Pardon P., Sanchis R., Marly J., Lantier F., Pépin M., Popoff M., Salmonellose ovine due à Salmonella abortusovis, Ann. Rech. Vét. 19 (1988) 221-235.

[37] Pardon P., Sanchis R., Marly J., Lantier F., Guilloteau L., Buzoni-Gatel D., Oswald I.P., Pépin M., Kaeffer B., Berthon P., Popoff M.Y., Experimental ovine salmonellosis (Salmonella abortusovis): pathogenesis and vaccination, Res. Microbiol. 141 (1990) 945-953. 
[38] Patterson H.D., Thomson W.A., Recovery of inter-block information when block sizes are unequal, Biometrika 58 (1971) 545-554.

[39] Pinard M.H., Van Arendonk J.A.M., Nieuwland M.G.B., Van der Zijpp A.J., Divergent selection for immune responsiveness in chickens: estimation of realized heritability with an animal model, J. Animal Sci. 70 (1992) 2986-2993.

[40] Pitel F., Cribiu E.P., Yerle M., Lahbib-Mansais Y., Lanneluc I., Lantier F., Gellin J., Regional localization of the ovine NRAMP gene to chromosome 2q41-q42 by in situ hybridisation, Cytogenet. Cell. Genet. 70 (1995) 116-118.

[41] Plant J., Glynn A.A., Locating Salmonella resistance gene on mouse chromosome 1, Clin. Exp. Immunol. 37 (1979) 1-6.

[42] Puel A., Mouton D., Genes responsible for quantitative regulation of antibody production, Critical Rev. Immunol. 16 (1996) 223-250.

[43] Ricordeau G., Tchamitchian L., Brunel J.C., Nguyen T.C., François D., La race Inra401 : un exemple de souche synthétique, in: Inra (Éd.), Génétique quantitative, Inra Production Animale hors série, 1992, pp. 255-262.

[44] $\mathrm{SAS}^{\circledR}$ (Statistical Analysis Systems) Institute, SAS ${ }^{\circledR}$ Procedures Guide. Version 6, 3rd edn., Cary, NC, USA, 1990, pp. 617-634.

[45] SAS $^{\circledR}$ (Statistical Analysis Systems) Institute, SAS ${ }^{\circledR} /$ STAT User's Guide. Version 6, 4th edn., Vol. 2, Cary, NC, USA, 1990, pp. 891-996.

[46] Sebastiani G., Olien L., Gauthier S., Skamene E., Morgan K., Gros P., Malo D., Mapping of genetic modulators of natural resistance to infection with Salmonella typhimurium in wild-derived mice, Genomics 47 (1998) 180-186.

[47] Shapiro S.S., Wilk M.B., An analysis of variance test for normality (complete samples), Biometrika 52 (1965) 591-610.

[48] Simianer H., Schaeffer L.R., Estimation of covariance components between one continuous and one binary trait, Genet. Sel. Evol. 21 (1989) 303-315.

[49] Sokal R.R., Rohlf F.J., Biometry: the principles and practice of statistics in biological research, 2nd edn., W.H. Freeman, New York, 1980, pp. 114-117.

[50] Vidal S.M., Malo D., Vogan K., Skamene E., Gros P., Natural resistance to infection with intracellular parasites: isolation of a candidate for $B c g$, Cell 73 (1993) 469-485.

[51] Wright S., An analysis of variability in number of digits in an inbred strain of guinea pigs, Genetics 19 (1934) 506-536.

\section{APPENDIX: EVALUATION OF THE POSSIBLE MATERNAL EFFECT ON LOG-IGG1.}

The estimation of $\log -\operatorname{IgG} 1_{0}$ heritability was different in the animal and sire models. To analyze this divergence, an animal model including a maternal genetic effect was tested to quantify this possible additional source of variation. The heritability of the direct effect estimated under this new model was close to the estimate obtained with a sire model, but the genetic maternal effect was small and had a correlation of 1 with the direct effect (Tab. VI).

This correlation of 1 being questionable, we explored the sources of difficulties in the estimation procedures. Convergence problems were unlikely 
Table VI. Estimations of $\log -\operatorname{IgG} 1_{0}$ genetic parameters under three uni-trait models.

\begin{tabular}{ll}
\hline Sire model & $h_{a}^{2}=0.12$ \\
Animal model & $h_{a}^{2}=0.28$ \\
Animal model with maternal effect & $h_{a}^{2}=0.11 \quad h_{m}^{2}=0.06 \quad \rho_{a, m}=1$ \\
\hline$h_{a}^{2}$ is the heritability of the direct effect, & $h_{m}^{2}$ of the maternal effect, $\rho_{a, m}$ the genetic \\
correlation between both effects. &
\end{tabular}

because the EM algorithm used converged to the same estimation whatever the starting solution given. Since performances were only recorded on the last generation, we tested the effect of the pedigree information on the quality of the estimation of the maternal genetic variance and the correlation between direct and maternal effects.

Simulations were done for a trait normally distributed and with the pedigree as observed in the real population. The heritabilities of the direct and maternal effect were always fixed at $h_{a}^{2}=0.11$ and $h_{m}^{2}=0.06$ respectively. The parameters varying between simulations were the genetic correlation between both effects and the number of generations with measurements $\left(n_{g}\right)$. Each situation was replicated 100 times.

Then, the direct effect heritability is correctly estimated for most of the cases simulated. The maternal effect heritability is on average slightly overestimated. The estimations of the genetic correlation vary between -1 and +1 for all studied situations, according to the very large standard deviation of this estimation. The estimations are much better when the performances are measured on more than 1 generation $\left(n_{g}=2\right.$ or 4$)$, being less biased and more precise. The pedigree structure of our population thus does not allow a correct estimation of the correlation between direct and maternal effects. Consequently, the direct effect heritability was estimated with a sire model.

To access this journal online: www.edpsciences.org 